
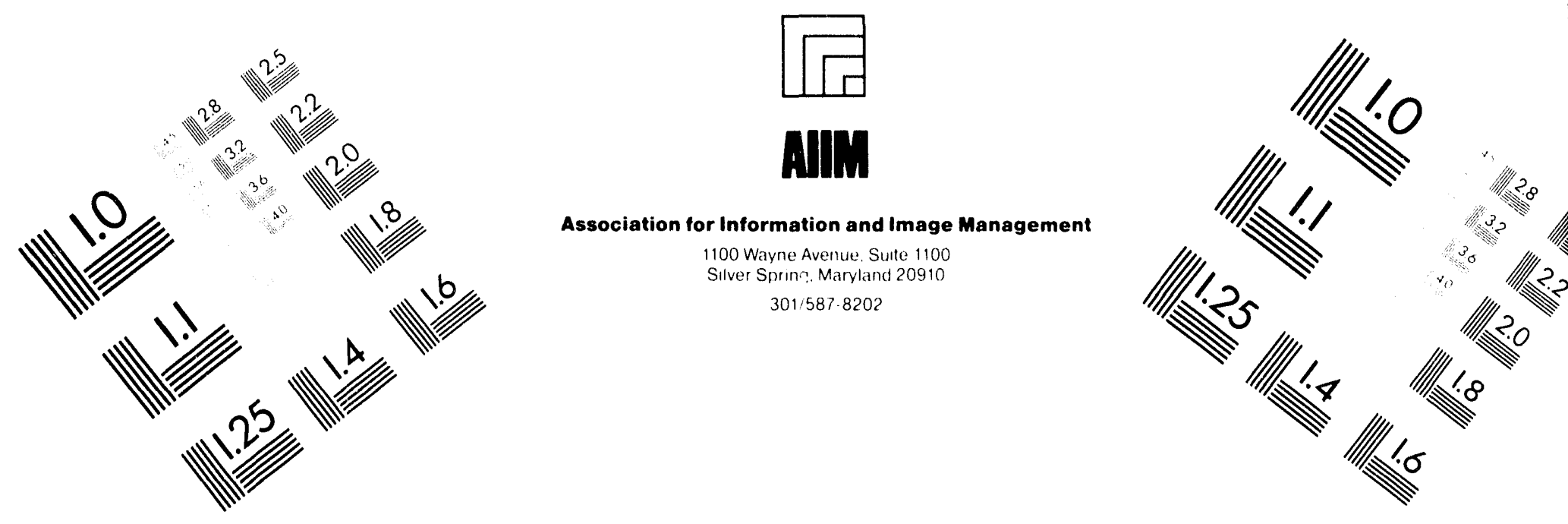

Centimeter

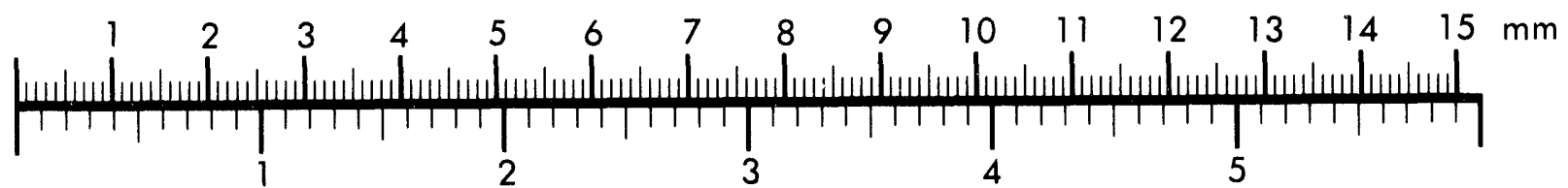

Inches
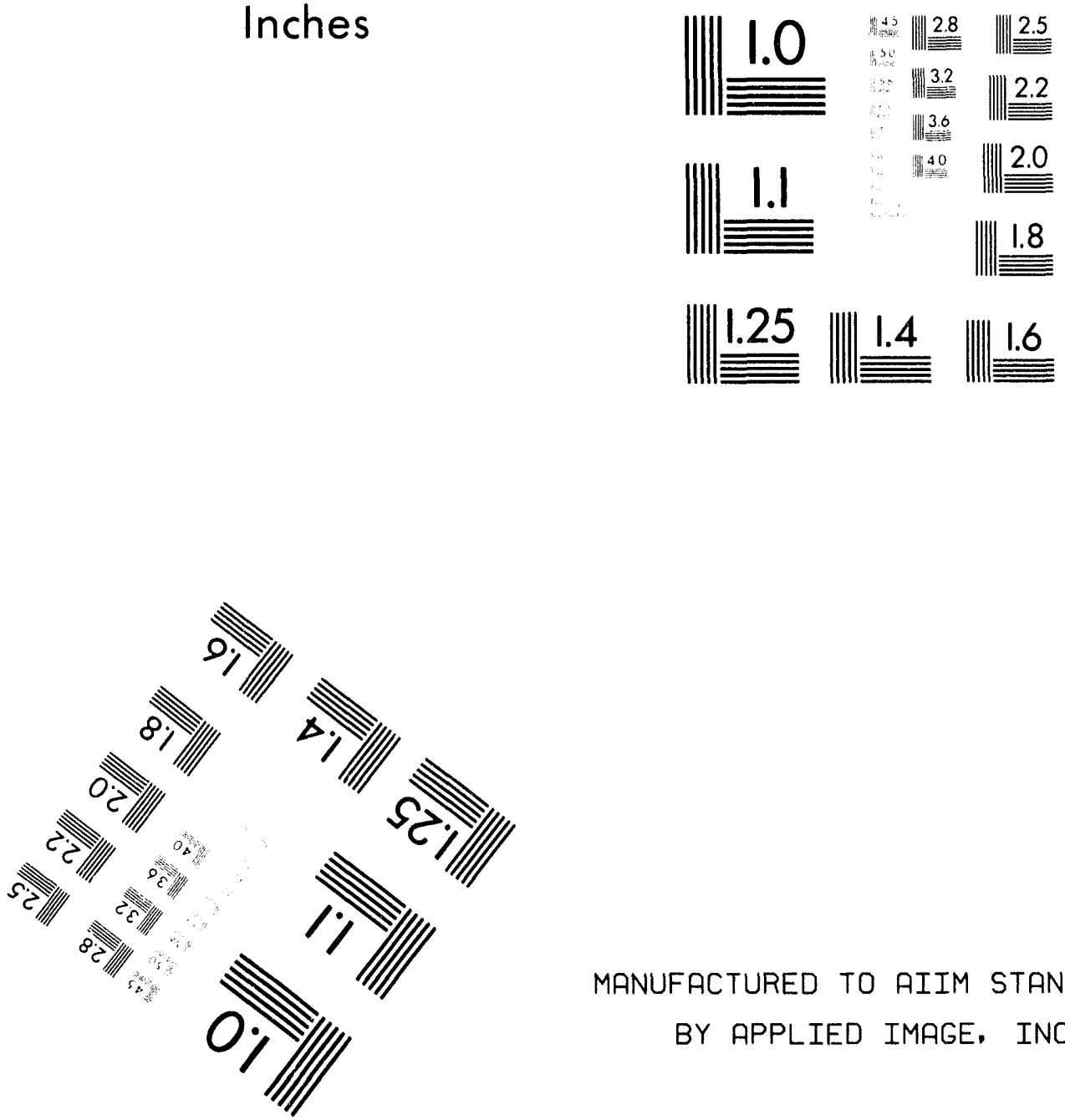

MANUFACTURED TO AIIM STANDARDS

BY APPLIED IMAGE, INC.

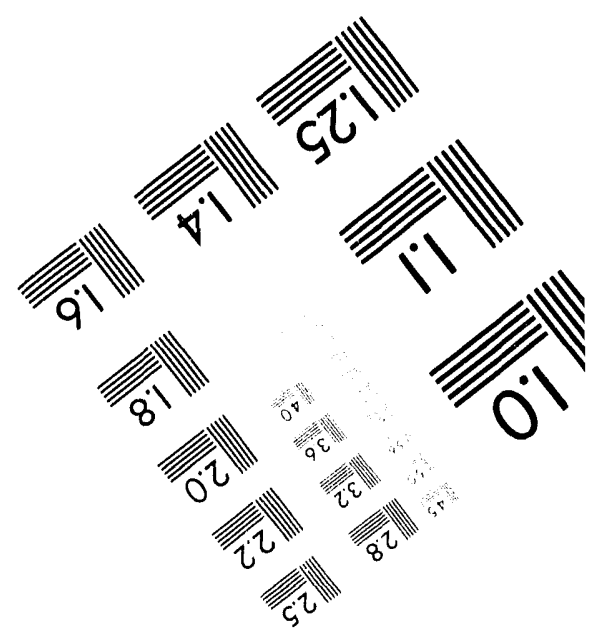



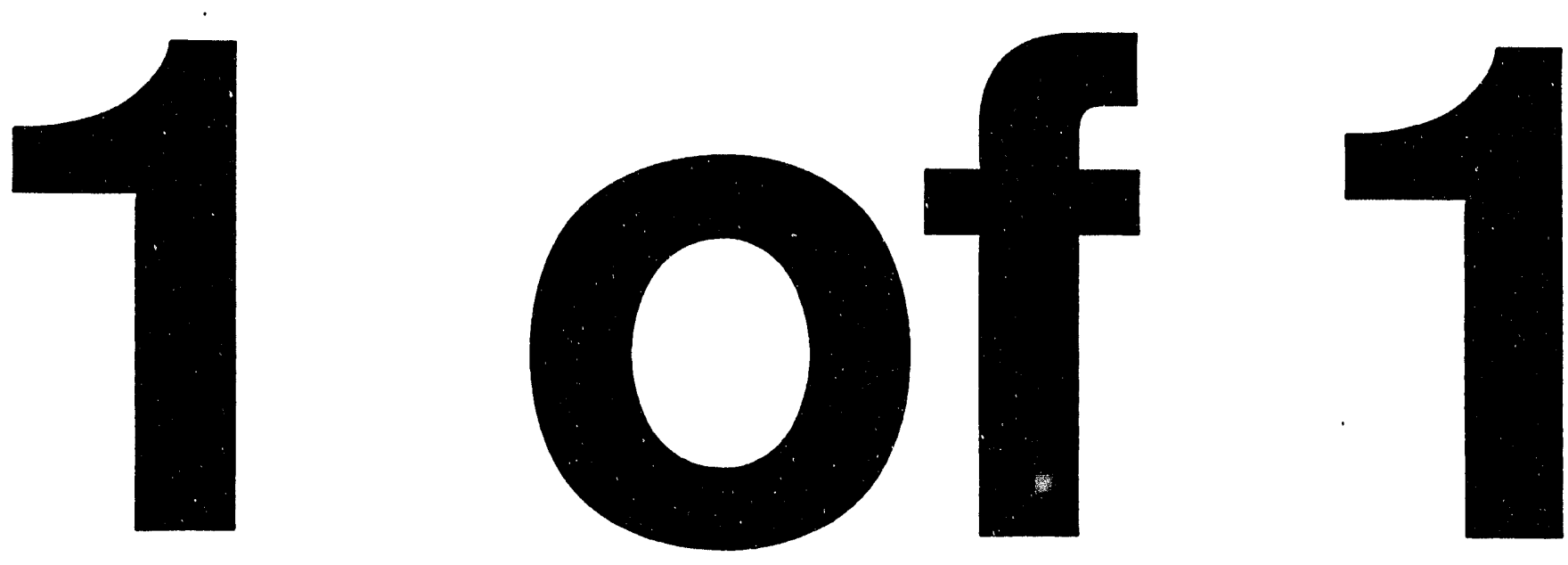


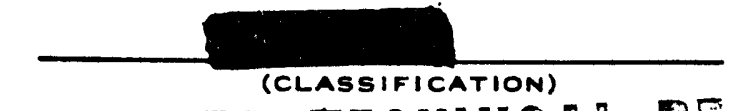

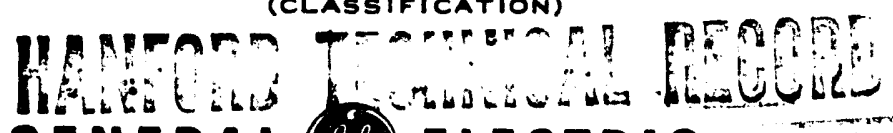

GENERAL (g\&) ELECTRIE : (G)

DATE

March 24, 1960

HANFORD ATOMIC PRODUCTS OPERATION - RICHLAND, WASHING Fón COPY NO. AND SERIES

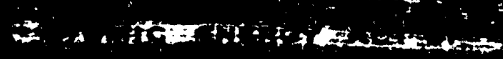

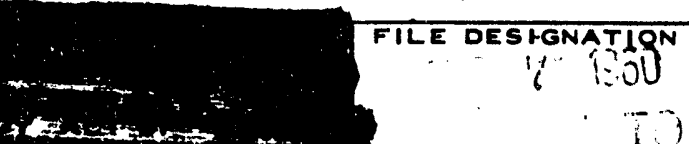

$+4$

OTHER OFFICIAL CLASSIFIED INFORMATION THIS MATERIAL CONTAINS INFORMATION AFFECTING THE NATIONAL DEFENSE OF THE UNITED STATES WITHIN THE MEANING OF THE ESPIONAGE LAWS, TITLE 18, U. S. C., EECS. T93 AND 794, THE TRANSMISSION OR REVELATION OF WHICH IN ANY MANNER TO AN UNAUTHORIZED PERSON IS PROHIBITED BY LAW.

\section{ATPH CORREIATION}

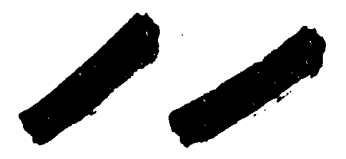

AUTHOR

\section{B. R. Cremer}

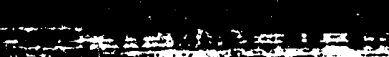 \\ wit. .

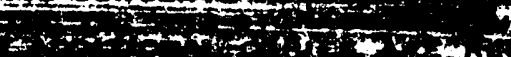

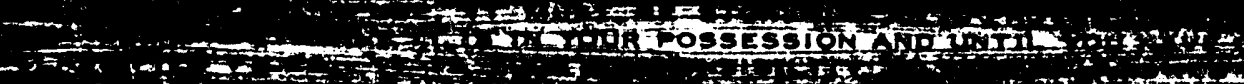

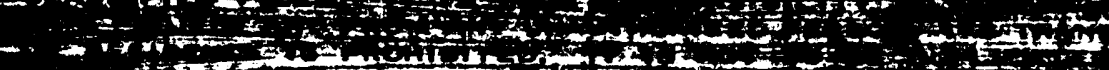

int

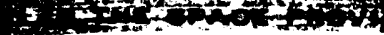

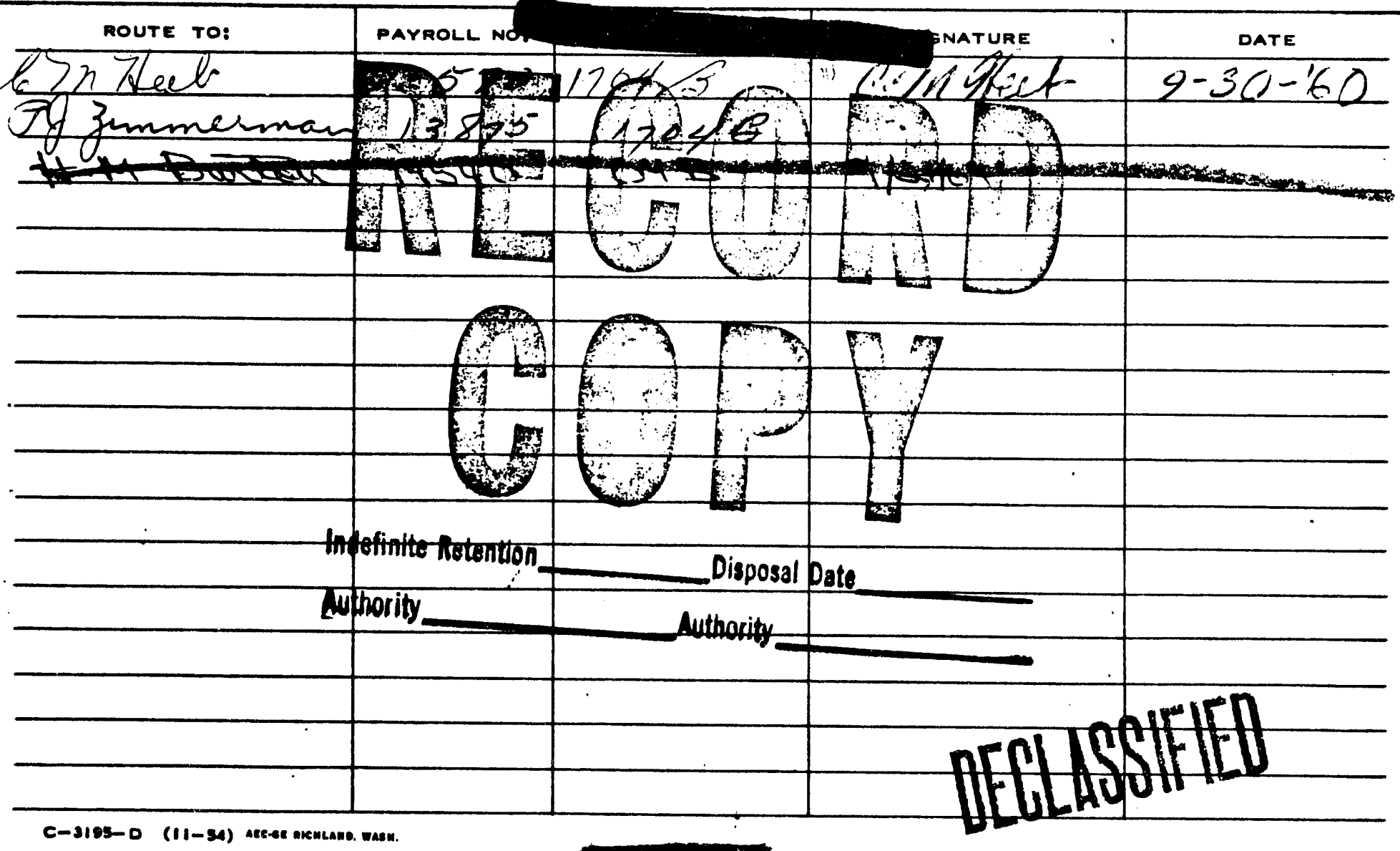

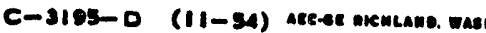

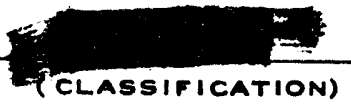


HWV -64454

\section{DISTRIBUTION}

1. JD Agar

2. Ji Benson

IfIf

By Authorty of $C Q-P R-2$, U) A Snudec, 1-19-94\%

verifict By 8 souely $1-3 /-94$
3. RR Bloomstrand

4. M clinton

5. BR Cremer

6. IIE Fuller

7. 8y Graves

8. CX Heeb

9. J Jaech

10. $\mathrm{ESB}$ Ieitz

11. WH Radtke

12. FW Reid

13. DL Renberger

14. A Russell

15. IEG Spencer

16. 300 Files

17. Record Center
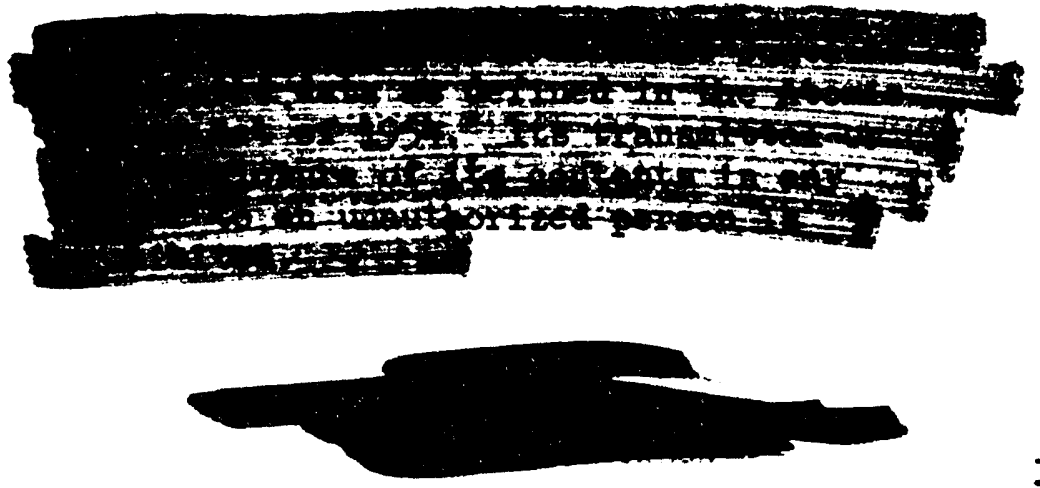

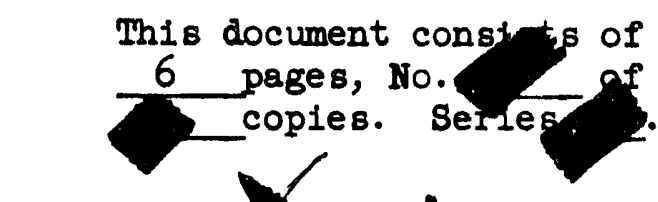

This docime effilied by

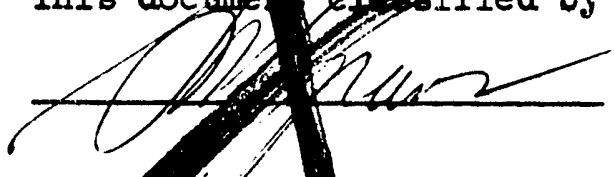

IRRADIATION ROgESS INO DEPARTMENT

March 24, 1960

AIPHA CORRELATION

\section{FURPOST}

This study was developed to provide a correlation for the evaluation of the pile $C_{R I} / T u b e C_{R I}$ ratio (alpha value) for each of the Hanford reactors.

\section{INTRODUCTION}

In the past, alpha values for all of the reactors have been estimated from a single correlation involving BCT/AT. Thls relationshlp, first proposed by Bloomstrand $(I)$,

(1) Current $C_{R}$ Values for Tubes and Methods to Calculate Plle $C_{R}$, Bloomstrand, RR, (Undocumented). 
has an advantage in being simple, but it lacks the precision afforded by some reIinements. Among other possible refinements is the correlation of alphe versus some other parameter than $\mathrm{BCT} / \mathrm{AT}$, and the correlation on an individual reactor bas18.

\section{SUMYARY AND COICIUSIONS}

By some transformations of the basic rupture equation (see discussion), an IBM program was rritten involving alpha as a function of individual tube powers and exposures. This program, in conjunction with factor distribution tapes, allowed the machine calculation of alpha values for all reactors. The alpha values were computed on a monthly basis for elght months out of 1959.

Jaech(2) was able to secure a very good correlation of the data by plotting alpha against $\overline{\mathrm{P}} / \mathrm{P}_{\text {Max. }}$. Instead of plotting alpha v8 $\overline{\mathrm{P}} / \mathrm{P}_{\text {Max }}$ individually for each reactor, he was able to group certain reactors together to generate only four curves instead of elght. The reactors were grouped on the basis of simllarity in distribution of their I \& $\mathbf{B}$ natural power factors. Thus, in the accompanying plots, $F$ and $C$ Reactors are plotted individually wile $B, D, D R$, and $H, K K_{\text {, }} K W$ are plotted as groups. Since It can be shown that $\bar{P} / P_{\text {Max }}$ is 1dentical to $(B C T)(I)$, the alpha for each reactor can be evaluated with good precision. Because (I) 18 relatively constant at any given reactor, the knowledge of BCT and the use of the appropriate plot will give the alpha value. The product of alpha and tube $C_{R I}$ will then yield the appropriate plle $C_{R I}$ value for use in the rupture equation.

\section{DIScUSSION}

The underlying premise in the development of the machine program is that the rupture rate of the plie is equal to the sumation of the individual tube rupture rates.

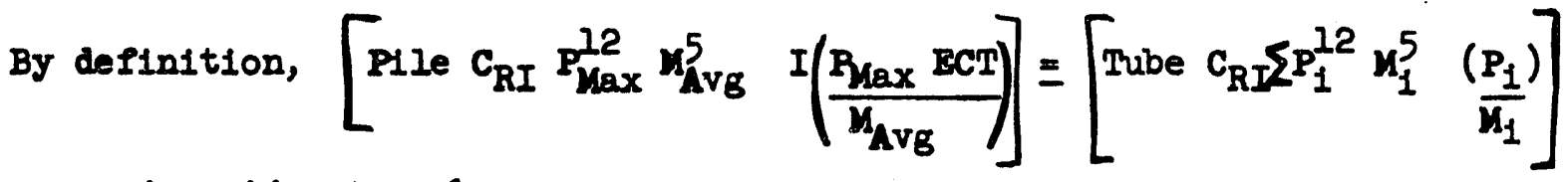

But, $I\left(P_{\text {Jax }}\right)(B C H) \equiv \sum P_{1}$

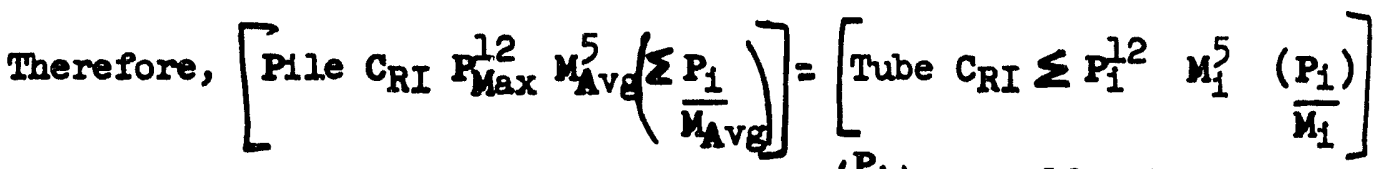

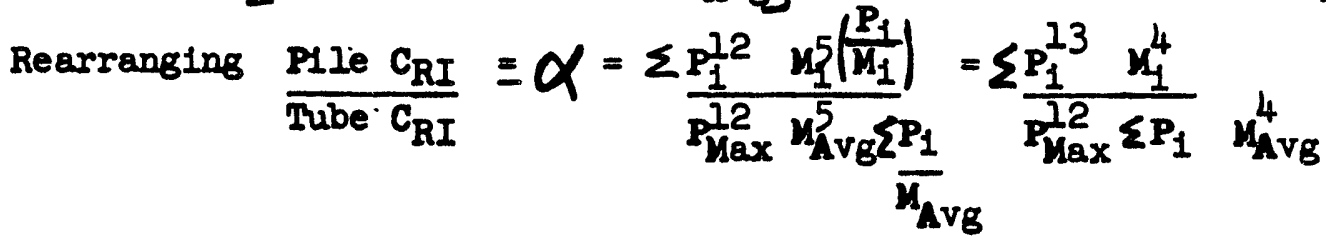

(2) J. I. Jaech, Operations Research and Synthesis, HWO.

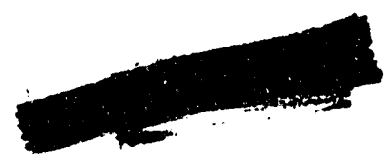




$$
\begin{aligned}
& \text { But, } u_{\Delta v g}=\sum u_{1}\left(\frac{P_{1}}{P_{1}}\right)=\sum P_{1} \\
& \sum\left(\frac{P_{1}}{M_{1}}\right) \sum\left(\frac{P_{1}}{M_{1}}\right) \\
& \text { Thus, } x_{\text {Avg }}^{4}=\left[\sum \frac{P_{1}}{\sum\left(\frac{P_{1}}{M_{1}}\right)}\right]^{4}
\end{aligned}
$$

Substituting Factors for Powers,

$$
\begin{aligned}
& \text { (A) } \alpha \equiv \Sigma\left(t_{1}^{13}\right) u_{1}^{4} \\
& f_{\operatorname{Max}}^{I_{2}} \Sigma\left(f_{1}\right)\left[\sum \frac{f_{1}}{\Sigma\left(\frac{f_{1}}{\mu_{1}}\right)}\right]^{4}
\end{aligned}
$$

Equation (A) was then used for the IBM run.

While $\overline{\mathbf{P}} / \mathbf{P}_{\text {yax }}$ was easily evaluated from $t$ he factor distribution tapes, it is not a convendent quantity to evaluate directly in normal practice. However, by definition $\overline{\mathbf{P}}=\frac{\left(\mathrm{R}_{\text {Max }}\right)(\mathrm{BCT})(\mathrm{I})}{\mathrm{N}}$. Therefore, $\overline{\mathbf{P}} / \mathrm{P}_{\text {Max }}=(\mathrm{BCT})\left(\frac{I}{\bar{N}}\right)$. Thus $\overline{\mathbf{P}} / \mathrm{P}_{\text {Max }}$ is related

to quantities which are easily measurable at each reaqtor.

\section{NONENCLATURE}

$\overline{\mathbf{P}}=$ average power of I \& $\mathbf{B}$ natural tubes.

$P_{\text {yax }}=$ average power of ten highest power tubes in pile.

$N=$ number of I \& $\mathrm{S}$ natural tubes in pile.

$\mathrm{BCT}$ = effective central tubes.

$I$ = percent of pile power generated by I \& $\mathbf{I}$ natural metal.

$C_{R I}=$ metal performance index for $I$ \& $E$ natural metal.

$\mathrm{M}_{\mathrm{Ag}}=$ average exposure of I \& $\mathrm{B}$ natural metal in pile.

$M_{1}=$ exposure of I \& $B$ natural metal in an individual tube.

$\Delta T=$ active tubes in pile.

TP = metal throughput.

$P_{1}=$ power of an individual tube.

$P_{1}=$ power factor of an individual tube $=\frac{\mathbf{P}_{1}}{\mathbf{P}}$.

BR Cremer:md

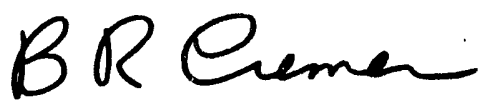




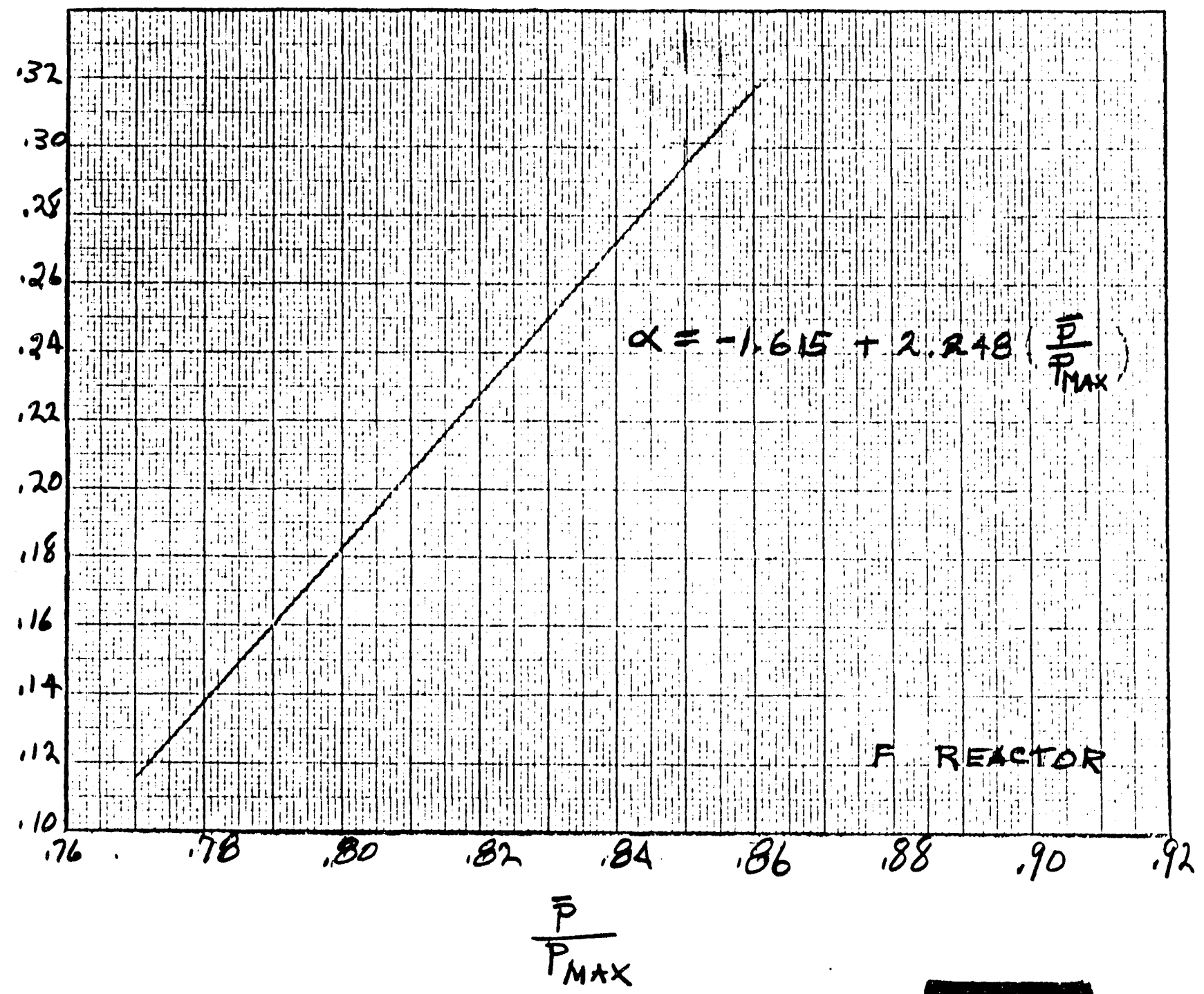



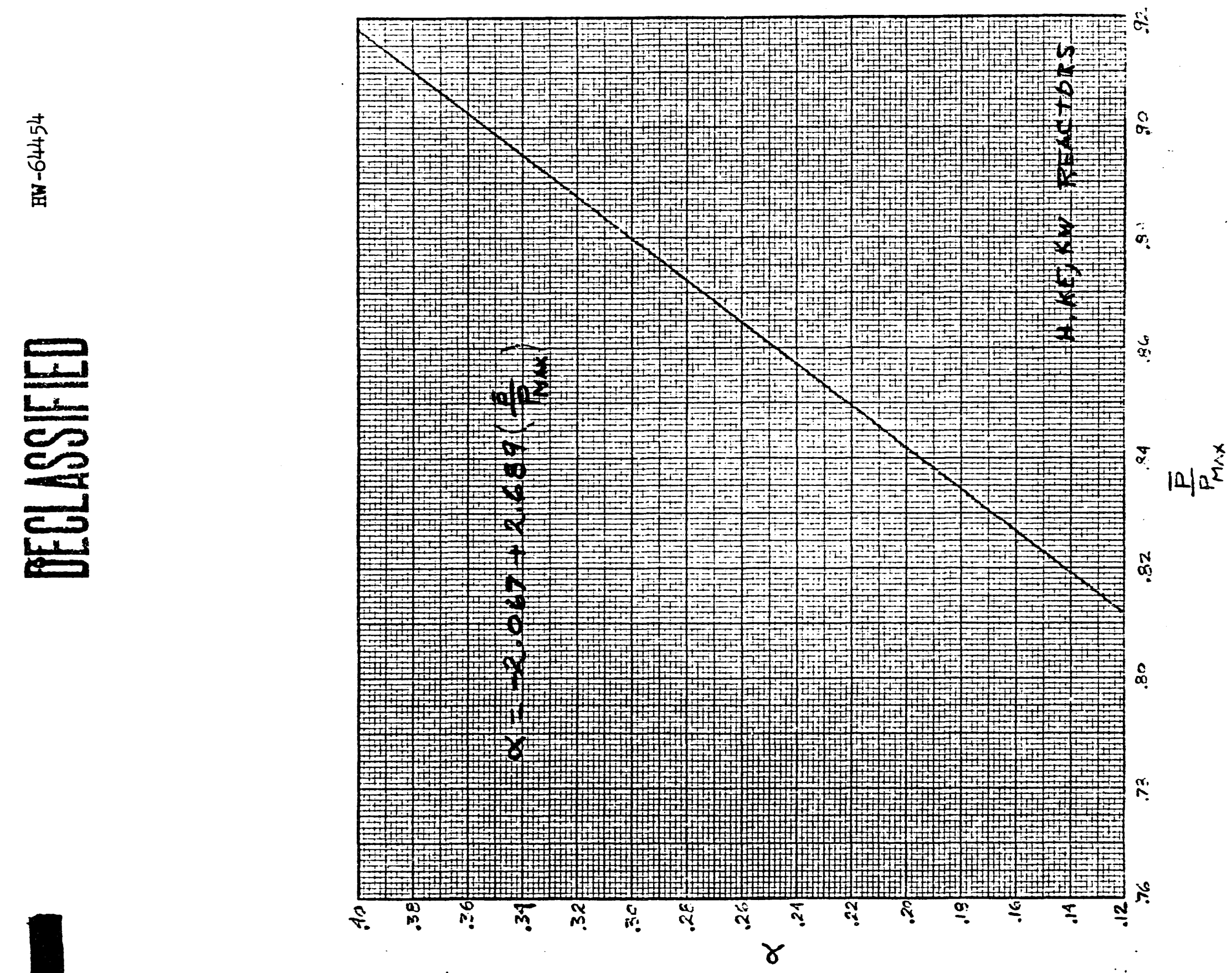

I 

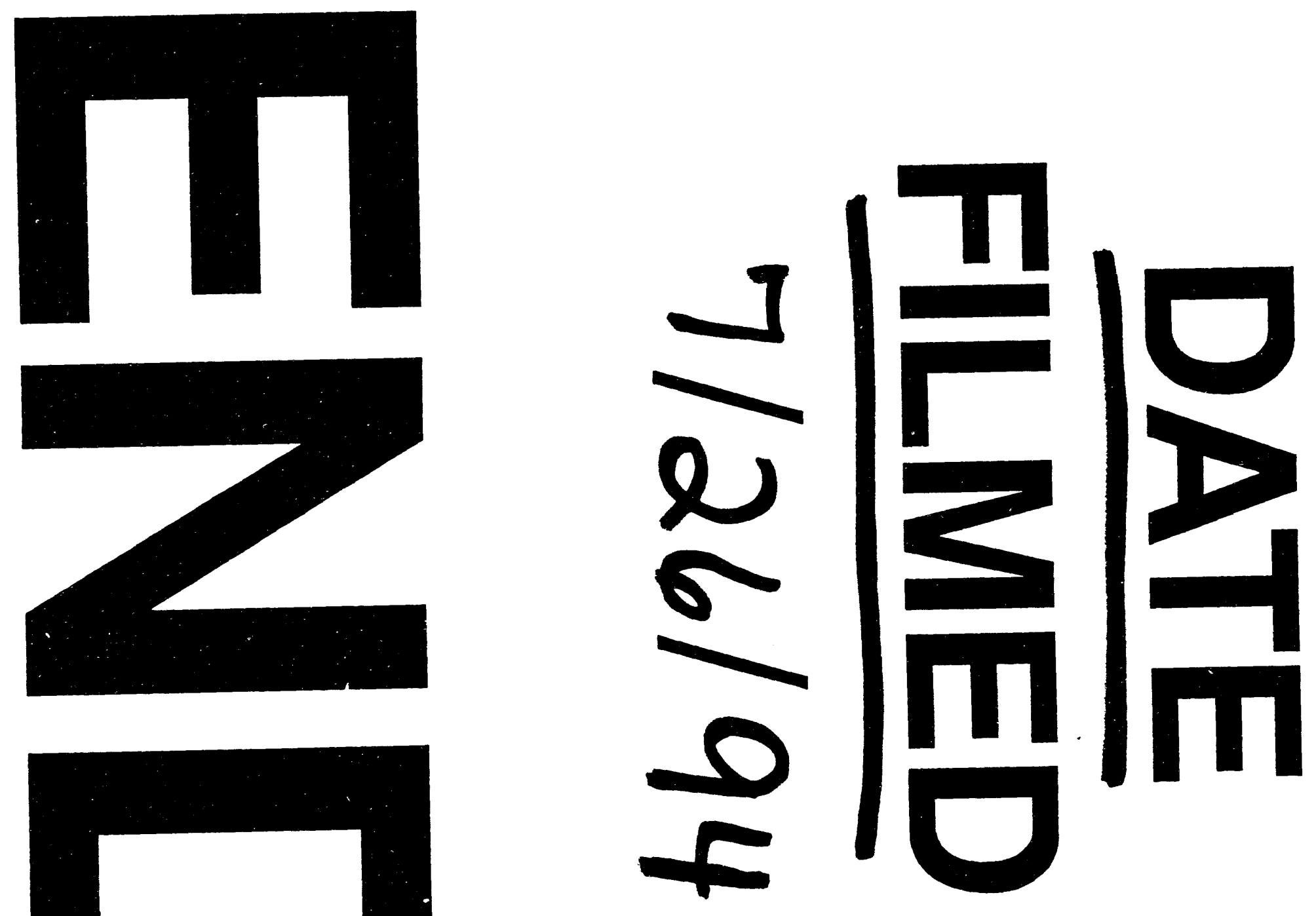
